\title{
Association between increased mutation rates in DNMT3A and FLT3-ITD and poor prognosis of patients with acute myeloid leukemia
}

\author{
QIURONG ZHANG, XIAO WU, JING CAO, FENG GAO and KUN HUANG
}

Department of Hematology, The Affiliated Zhangjiagang Hospital of Soochow University, Suzhou, Jiangsu 215600, P.R. China

Received October 31, 2018; Accepted April 11, 2019

DOI: $10.3892 /$ etm.2019.7891

\begin{abstract}
A total of 133 patients with acute myeloid leukemia (AML) were enrolled in the current study and were subdivided into 4 groups: 34 harboring DNA methyltransferase $3 \alpha$ (DNMT3A) + fms related tyrosine kinase 3-internal tandem duplication (FLT3-ITD) mutations, 37 harboring only FLT3-ITD mutation, 32 harboring only DNMT3A mutation and 30 harboring no mutations in DNMT3A and FLT3-ITD (control). Patients in all groups were administered daunorubicin and cytarabine chemotherapy regimens. The rates of complete remission (CR), 1-year relapse (RR) and 3 -year overall survival (OS) were compared. Patients in the DNMT3A + FLT3-ITD mutation group exhibited higher proportions of peripheral white blood cells (WBCs) and myeloid progenitor cells compared with those in DNMT3A mutation only, FLT3-ITD mutation only and control groups $(\mathrm{P}<0.05)$. The rates of $\mathrm{CD} 15^{+}$and HLA-DR ${ }^{+}$in the DNMT3A + FLT3-ITD mutation and DNMT3A mutation only groups were significantly higher than those in the FLT3-ITD mutation only and control groups $(\mathrm{P}<0.05)$; in addition, the rate of $\mathrm{CD} 38^{+}$in the DNMT3A + FLT3-ITD mutation and FLT3-ITD mutation only groups was significantly higher compared with that in the DNMT3A mutation only and control groups $(\mathrm{P}<0.05)$. The overall chemotherapy effectiveness rate, CR, 1-year RR and the 3-year OS rates of patients in the DNMT3A + FLT3-ITD mutation group were significantly worse compared with FLT3-ITD mutation only, DNMT3A mutation only and control groups $(\mathrm{P}<0.05)$. The results of this study indicated that increased mutation rates in DNMT3A and FLT3-ITD may be associated with increased WBC and myeloid progenitor cell
\end{abstract}

Correspondence to: Dr Kun Huang, Department of Hematology, The Affiliated Zhangjiagang Hospital of Soochow University, 68 Jiyang West Road, Zhangjiagang, Suzhou, Jiangsu 215600, P.R. China E-mail: kunhuangmmm@163.com

Key words: DNA methyltransferase $3 \alpha$, fms related tyrosine kinase 3-internal tandem duplication, mutation rate, acute myeloid leukemia, prognosis counts, an inferior chemotherapy efficacy and prognosis, a lower CR rate, and higher 1-year RR and mortality rate.

\section{Introduction}

Acute myeloid leukemia (AML), the most common phenotype of adult acute leukemia, is a malignancy caused by the aberrant cloning and hyperplasia of hematopoietic stem cells in the hemopoietic system (1). Cytogenetic analysis is considered an important method for prognostic evaluation (2). Patients with AML with a normal karyotype contain the largest cytogenetic population (3). However, in-depth molecular genetics studies revealed that mutations may be critical independent risk factors associated with the prognosis of patients with AML (4); additionally, the prognosis of patients with AML with a normal karyotype has been demonstrated to differ from those harboring mutations in different genes (5).

The DNA methyltransferase $3 \alpha$ (DNMT3A) gene is located on chromosome 2p23 and is highly expressed in adults (6). A recent analysis of genetic mutations in patients with AML revealed that the DNMT family of proteins is aberrantly upregulated, with the resulting hypermethylation of tumor suppressor genes a potential driver in leukemia development (7). In addition, a previous study demonstrated that a certain proportion of DNMT3A mutations exist in the normal karyotypes of patients with AML, which may be an independent risk factor for the poor prognosis (8). Although previous studies demonstrated the key role of DNMT3A-mediated methylation in patients with AML, the effect of DNMT3A mutation on AML prognosis remains unclear $(9,10)$. FMS-like tyrosine kinase-3 (FLT3) is a member of the growth factor receptor family with endonuclease activity towards tyrosine kinase. In particular, FLT3-internal tandem duplication (ITD) is the most common mutation found in the FLT3 gene (11). It has been reported that patients with AML carrying the FLT3-ITD mutation display a higher peripheral white blood cell (WBC) count, which severely affects the rates of complete remission (CR), relapse (RR) and overall survival (OS) (12). FLT3-ITD mutation eliminates the autoinhibition of FLT3, resulting in the activation of downstream proliferative signaling pathways affecting the proliferation of cells carrying FLT3 mutations n patients with AML (13). Although FLT3-ITD is reported at high rates amongst patients with AML (14), large-sample studies examining this mutation are lacking. 
Therefore, in the present study associations between DNMT3A and/or FLT3-ITD mutations and prognostic indicators were analyzed in patients with AML to provide a molecular method for the prognosis evaluation, and a potential foundation for personalized therapy.

\section{Materials and methods}

General data. A retrospective analysis was performed on data of the clinical features and prognosis obtained from 133 patients diagnosed with AML between January 2010 and June 2015. Amongst these patients, 74 were male and 59 were female with the age range between 18-61 years old. According to French-American-British (FAB) classification of AML (15), there were 3,13,50, 27, 14, 22 and 4 patients classified with the M0, M1, M2, M3, M4, M5 and M6 subtypes, respectively, with 0 mixed subtypes. Patients were grouped according to genetic mutations detected by next-generation sequencing: 34 patients harboring mutations in DNMT3A and FLT3-ITD were enrolled into the DNMT3A + FLT3-ITD mutation group, 37 patients harboring mutations in FLT3-ITD only were enrolled into the FLT3-ITD mutation group, 32 patients harboring mutations in DNMT3A only were enrolled into the DNMT3A mutation only group and 30 patients harboring no DNMT3A and FLT3-ITD mutations were designated as the control group. Patients in all groups were administered daunorubicin and cytarabine chemotherapy regimens. The following inclusion criteria were used: i) Patients who were diagnosed with AML by bone marrow cell morphology analysis; and ii) genetic mutation was confirmed with examination of chromosome and fusion genes. The following exclusion criteria were used: i) Patients afflicted with severe diseases of other organs; ii) patients with other tumors; iii) patients with cognitive dysfunction resulting in difficulties in negotiation confirmed via face-to-face communication; and iv) patients who can not participate in the study. All patients and respective families agreed to participate in the study and signed written informed consent. This study was approved by the Ethics Committee of The Affiliated Zhangjiagang Hospital of Soochow University.

\section{Experiment methods}

Experimental materials and reagents. The equipment and reagents used in the current study included: XE-2100D Automatic Analyzer(Sysmex Asia Pacific Pte.Ltd.), fetal bovine serum (Hyclone; GE Healthcare), daunorubicin (State Food and Drug Administration of China [SFDA] no. H33020925; Zhejiang Hisun Chemical Co., Ltd.), cytarabine (registration no. H20100594; Actavis; Teva Pharmaceutical Industries Ltd.), daunorubicin (SFDA no. H20040600; Guangdong Leawell Pharmaceutical Co., Ltd.), mitoxantrone (SFDA no. H10960119; Zhejiang Ruixin Pharmaceutical Co., Ltd.) and etoposide (SFDA no. H53021627; KPC Pharmaceutical, Inc.). Bovine serum albumin (BSA; SFDA no. A104912-5g; Shanghai Aladdin Biochemical Technology Co., Ltd.), fluorescein isothiocyanate (CAS Number: 27072-45-3; Sigma-Aldrich; Merck KGaA), phycoerythrin (552603; BD PharMingen) and allophycocyanin (553051; BD PharMingen).

Comparison of indicators before and after treatment. The following were collected from the patients in the four groups:
A total of $4 \mathrm{ml}$ venous blood was collected to perform peripheral blood cell counts using the XE-2100D automatic analyzer according to the manufacturer's protocol. Parameters included WBC, platelet and hemoglobin counts, and proportions of myeloid progenitor cells, including WBC, platelet and hemoglobin counts, and proportions of myeloid progenitor cells. A total of $0.1 \mathrm{ml}$ marrow was collected as previously described in the literature (16) to perform bone marrow smears for the counting of karyocytes (17) stained with Wright's stain under a microscope, to calculate the number of myeloid progenitor cells; and $1 \mathrm{ml}$ marrow was collected to prepare specimens for immunogenotyping.

Flow cytometry to determine immunogenotypes. For immunogenotyping, fluorescence-conjugated antibodies were added to $100 \mu \mathrm{l}$ marrow specimens in each reaction, which were then diluted with 100-200 $\mu \mathrm{l}$ phosphate-buffered saline supplemented with $2 \%$ BSA. The fluorescein antibodies labeled with fluorescein isothiocyanate/phycoerythrin/allophycocyanin were added at $5 \mu \mathrm{l}$ respectively.

The samples were subsequently subjected to shaking incubation in a dark room at room temperature for 25-30 min, followed by incubation with $1.5 \mathrm{ml}$ red blood cell lysis buffer (1X) in a dark room at room temperature for 15-20 min. Following centrifugation at $780 \mathrm{x} \mathrm{g}$ under room temperature, the supernatant was discarded, and the pellet was subsequently mixed with phosphate-buffered saline supplemented with $2 \%$ BSA to determine the immunogenotypes using flow cytometry.

Chemotherapy regimens. The first treatment course were performed as follows: Daunorubicin $\left(40-60 \mathrm{mg} / \mathrm{m}^{2} ; 1\right.$ time/day; days $1-3)+$ cytarabine $\left(100-200 \mathrm{mg} / \mathrm{m}^{2} ; 1\right.$ time/day; days $\left.1-7\right)$ or darubicin $\left(8-10 \mathrm{mg} / \mathrm{m}^{2} ; 1\right.$ day/day; days $\left.1-3\right)+$ cytarabine $\left(100-200 \mathrm{mg} / \mathrm{m}^{2} ; 1\right.$ time/day; days $\left.1-7\right)$, which was selected on basis of the patient's economic situation (higher dose treatment for patients in better economic situation). Doses were adjusted upon infection or according to results of blood tests obtained routinely from the patients during treatment. Patients exhibiting no remission following the first treatment course were subjected to the mitoxantrone (MEA) regimen in the second treatment course: Mitoxantrone (4 $\mathrm{mg} / \mathrm{m}^{2}$; days 1-3) + etoposide (100 mg; days $4-6)+$ cytarabine $\left(150 \mathrm{mg} / \mathrm{m}^{2}\right.$; days 1-7); whereas patients displaying significant remission were administered with the same doses for the second treatment course.

Observation indices. WBC, platelet and hemoglobin counts in addition to the proportion of myeloid progenitor cells at onset time in the four patient groups were observed and compared (Table I). The immunogenotypes of patients in the four groups at the time of onset were also observed. RECIST 1.1 criteria (18) were adopted to evaluate chemotherapy efficacy in patients from the four groups using the following four categories: Complete remission (CR), partial remission (PR), stable disease (SD) and progressive disease (PD). Effectiveness rate $=(C R+P R) /$ total no of patients $(\mathrm{CR}+\mathrm{PR}+\mathrm{SD}+\mathrm{PD}) \times 100 \%$. The following CR criteria were used: Patients exhibiting no symptoms or signatures of leukemia with no compromise to the quality of life or $\mathrm{Hb}$ $\geq 90 \mathrm{~g} / 1$, absolute value of neutrophils $\geq 1.5 \times 10^{9} / 1$, platelet 
Table I. Comparison of leukocyte count, platelet count, hemoglobin count and myeloid progenitor cells in the four groups of patients at onset.

\begin{tabular}{|c|c|c|c|c|c|c|}
\hline Index & $\begin{array}{c}\text { DNMT3A + FLT3-ITD } \\
\text { mutation } \\
\text { group } n=34\end{array}$ & $\begin{array}{l}\text { FLT3-ITD } \\
\text { mutation only } \\
\text { group } n=37\end{array}$ & $\begin{array}{l}\text { DNMT3A } \\
\text { mutation only } \\
\text { group } n=32\end{array}$ & $\begin{array}{c}\text { Control } \\
\text { group } n=30\end{array}$ & F statistic & P-value \\
\hline White blood cells (x109/1) & $79.31 \pm 21.24$ & $44.05 \pm 12.09^{\mathrm{a}, \mathrm{b}}$ & $39.78 \pm 11.69^{\mathrm{a}, \mathrm{b}}$ & $33.14 \pm 9.10^{\mathrm{a}}$ & 68.01 & $<0.001$ \\
\hline Platelet (x109/1) & $48.60 \pm 35.23$ & $44.61 \pm 7.97$ & $41.40 \pm 7.59$ & $36.29 \pm 6.38$ & 2.414 & 0.070 \\
\hline Hemoglobin (g/l) & $71.33 \pm 6.87$ & $72.24 \pm 2.73$ & $69.60 \pm 4.84$ & $62.11 \pm 4.23$ & 28.11 & $<0.001$ \\
\hline Myeloid progenitor cells (\%) & $0.91 \pm 0.05$ & $0.62 \pm 0.04^{\mathrm{a}, \mathrm{b}}$ & $0.64 \pm 0.03^{\mathrm{a}, \mathrm{b}}$ & $0.57 \pm 0.03^{\mathrm{a}}$ & 518.0 .3 & $<0.001$ \\
\hline
\end{tabular}

${ }^{a} \mathrm{P}<0.05$ vs. DNMT3A + FLT3-ITD mutation group; ${ }^{\text {} P<0.05 ~ v s . ~ c o n t r o l ~ g r o u p . ~ D N M T 3 A, ~ D N A ~ m e t h y l t r a n s f e r a s e ~ 3 \alpha ; ~ F L T 3-I T D, ~ F M S-l i k e ~}$ tyrosine kinase-internal tandem duplication.

Table II. General patient data.

\begin{tabular}{|c|c|c|c|c|c|c|}
\hline Factor & $\begin{array}{c}\text { DNMT3A + FLT3-ITD } \\
\text { mutation group } \\
\mathrm{n}=34(\%)\end{array}$ & $\begin{array}{c}\text { FLT3-ITD } \\
\text { mutation only } \\
\text { group } n=37(\%)\end{array}$ & $\begin{array}{c}\text { DNMT3A } \\
\text { mutation only } \\
\text { group } n=32(\%)\end{array}$ & $\begin{array}{c}\text { Control group } \\
n=30(\%)\end{array}$ & $\chi^{2}$ & P-value \\
\hline Gender & & & & & 0.089 & 0.993 \\
\hline Male & $19(55.88)$ & $21(56.76)$ & $18(56.25)$ & $16(53.33)$ & & \\
\hline Female & $15(44.12)$ & $16(43.24)$ & $14(43.75)$ & $14(46.67)$ & & \\
\hline Age (years) & & & & & 0.696 & 0.874 \\
\hline$<50$ & $14(41.18)$ & $15(40.54)$ & $11(34.38)$ & $10(33.33)$ & & \\
\hline$>50$ & $20(58.82)$ & $22(59.46)$ & $21(65.63)$ & $20(66.66)$ & & \\
\hline Body mass index $\left(\mathrm{kg} / \mathrm{m}^{2}\right)$ & & & & & 0.905 & 0.824 \\
\hline$<22$ & $15(44.12)$ & $17(45.95)$ & $17(53.13)$ & $16(53.33)$ & & \\
\hline$>22$ & $19(55.88)$ & $20(54.05)$ & $15(46.88)$ & $14(46.67)$ & & \\
\hline Smoking & & & & & 0.035 & 0.998 \\
\hline Yes & $16(47.06)$ & $18(48.65)$ & $15(46.88)$ & $14(46.67)$ & & \\
\hline No & $18(52.94)$ & $19(51.35)$ & $17(53.13)$ & $16(53.33)$ & & \\
\hline Drinking & & & & & 0.018 & 0.999 \\
\hline Yes & $21(61.76)$ & $23(62.16)$ & $20(62.50)$ & $19(63.33)$ & & \\
\hline No & $13(38.24)$ & $14(37.84)$ & $12(37.50)$ & $11(17.46)$ & & \\
\hline FAB classification & & & & & 1.710 & 1.000 \\
\hline M0 & $1(2.94)$ & $1(2.70)$ & 0 & $1(3.33)$ & & \\
\hline M1 & $3(8.82)$ & $4(10.81)$ & $3(9.38)$ & $3(10.00)$ & & \\
\hline M2 & $13(38.24)$ & $14(37.84)$ & $12(37.50)$ & $11(36.67)$ & & \\
\hline M3 & $6(17.65)$ & $8(22.86)$ & $7(21.88)$ & $6(20.00)$ & & \\
\hline M4 & $4(11.76)$ & $3(8.11)$ & $4(12.50)$ & $3(9.99)$ & & \\
\hline M5 & $6(17.65)$ & $6(16.22)$ & $5(15.63)$ & $5(16.67)$ & & \\
\hline M6 & $1(2.94)$ & $1(2.70)$ & $1(3.13)$ & $1(3.33)$ & & \\
\hline Mixed type & 0 & 0 & 0 & 0 & & \\
\hline
\end{tabular}

FAB, fragment antigen-binding; DNMT3A, DNA methyltransferase 3 $\alpha$; FLT3-ITD, FMS-like tyrosine kinase-internal tandem duplication.

$\geq 100 \times 10^{9} / 1, \leq 5 \%$ myeloblast (type I+II) and normal ery throcyte and megakaryocytic series. The following PR criteria were used: Patients demonstrating 5-20\% myeloblast (type I+II) or one or more indicators failing to meet the CR criterion. The following SD criteria were used: Chemotherapy exerted no overall effects on patients. The following PD criteria were used: Patients exhibiting no remission but showing disease progression following chemotherapy. After the CR rates of the patients in the four groups were calculated, the 1-year RR and 3-year OS rate of patients were subsequently compared through 3-year follow-up. The following were used as criteria for PR: Patients who achieved complete remission following 


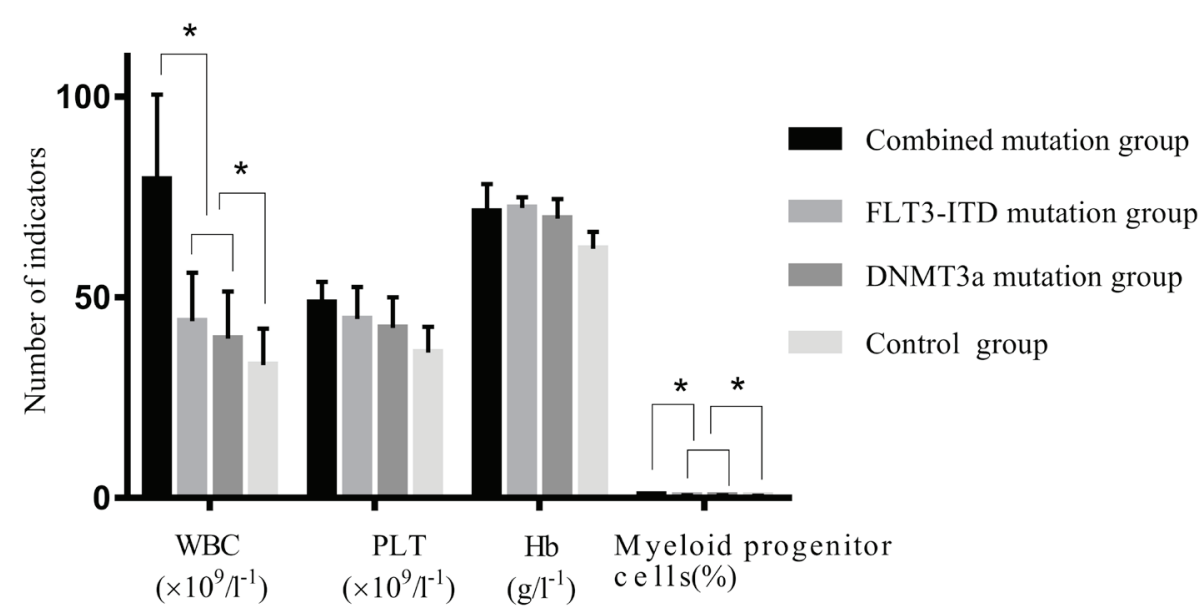

Figure 1. Comparison of WBC, PLT and $\mathrm{Hb}$ counts in addition to the ratio of myeloid progenitor cells in the four patient groups at onset. The proportion of WBC and myeloid progenitor cells in the peripheral blood of the DNMT3A + FLT3-ITD mutation group was significantly higher compared with that in the FLT3-ITD mutation only and DNMT3A mutation only groups. No statistically significant differences were found in the count of blood platelets and hemoglobin among the four groups. ${ }^{*} \mathrm{P}<0.05$ with comparisons indicated by lines. DNMT3A, DNA methyltransferase $3 \alpha$; FLT3-ITD, FMS-like tyrosine kinase-internal tandem duplication; WBC, white blood cells; PLT, platelets; Hb, haemoglobin.

treatment exhibiting 5-20\% myeloblasts (type I+II) and did not satisfy the CR criterion specific for myelogram following one course of effective treatment. Relapse rate=number of relapsed people within 1 year/total number of people.

Following complete remission, the patient's bone marrow myeloblast I + type II (primary mononuclear + naive monocytes or primordial lymph + naive lymphocytes) $>5$ and $\leq 20 \%$, and they cannot achieve complete remission following a course of effective anti-leukemia treatment, or patients displaying myeloblast (type I+II) $>20 \%$. OS time was defined as the time period the between the day of diagnosis to all-cause mortality or the end of follow-up.

Statistical analysis. All data were analyzed using SPSS 18.0 software (SPSS, Inc.). Measurement data are presented as the mean \pm standard deviation, and $\geq 3$ means were compared using one-way analysis of variance followed by Bonferroni post-hoc test. Nominal data were compared using the $\chi^{2}$ test. The Kaplan-Meier survival analysis was prepared using GraphPad Prism 6 (GraphPad Software, Inc.). P $<0.05$ was considered to indicate a statistically significant difference.

\section{Results}

Baseline data comparison. Comparisons of gender, age and FAB subtypes among patients of the four groups revealed no statistically significant differences ( $\mathrm{P}>0.05$; Table II).

$W B C$, platelet and hemoglobin counts, and proportions of myeloid progenitor cells in patients at the time of onset. In the DNMT3A + FLT3-ITD group, the peripheral WBC count and proportion of myeloid progenitor cells were significantly higher than those in the FLT3-ITD mutation only, DNMT3A mutation only and control patient groups (all $\mathrm{P}<0.05$ ), but no significant differences were observed in the platelet count and hemoglobin levels in the peripheral blood of patients across the four groups ( $\mathrm{P}>0.05$; Fig. 1; Table I). The WBC count and proportion of myeloid progenitor cells in the FLT3-ITD mutation only and DNMT3A mutation only patient groups were significantly higher compared with the control group $(\mathrm{P}<0.05)$; but exhibited no significant differences when compared with each other ( $\mathrm{P}>0.05$; Fig. 1; Table I).

Comparison of immunogenotypes of patients across the four groups. The $\mathrm{CD}^{+} 5^{+}$and $\mathrm{HLA}-\mathrm{DR}^{+}$rates were significantly higher in the DNMT3A + FLT3-ITD mutation and DNMT3A mutation only patient groups compared with those in the FLT3-ITD mutation only and control groups $(\mathrm{P}<0.05)$. In addition, the rates of $\mathrm{CD} 38^{+}$in the DNMT3A + FLT3-ITD mutation and FLT3-ITD mutation only patient groups were significantly higher compared with that in the DNMT3A mutation only and control groups $(\mathrm{P}<0.05)$. Comparison between the four patient groups demonstrated no significant differences in the rates of $\mathrm{CD} 34^{+}, \mathrm{CD} 33^{+}, \mathrm{CD} 13^{+}, \mathrm{CD} 14^{+}$and $\mathrm{CD}_{117^{+}}(\mathrm{P}>0.05$; Table III).

Evaluation of chemotherapy efficacy in patients across the four groups. The overall rate of chemotherapy effectiveness was $38.24 \%$ in the DNMT3A + FLT3-ITD mutation patient group, which was significantly lower compared with 70.27 , 71.88 and $83.33 \%$ in the FLT3-ITD mutation only, DNMT3A mutation only and control patient groups, respectively $(\mathrm{P}<0.05)$. Comparison of the overall effectiveness rates of chemotherapy between the DNMT3A only and FLT3-ITD only groups revealed no statistically significant differences (P>0.05), but were significantly lower when compared with the control group $(\mathrm{P}<0.05$; Table IV).

Comparison of $C R$ rates, 1-year $R R$ and 3-year $O S$ rates of patients between the four groups. In the DNMT3A + FLT3-ITD group, the CR rate of patients was $11.76 \%$, which was significantly lower compared with $37.84,40.63$ and $50.00 \%$ in the FLT3-ITD mutation only, DNMT3A mutation only and control patient groups respectively $(\mathrm{P}<0.05)$. Although DNMT3A mutation only and FLT3-ITD mutation only patient groups displayed no significant differences 
Table III. Comparison of immunological positive rates in the four patient groups.

\begin{tabular}{|c|c|c|c|c|c|c|}
\hline Immunogenotype & $\begin{array}{c}\text { DNMT3A + FLT3-ITD } \\
\text { mutation group } \\
\text { n=34 }(\%)\end{array}$ & $\begin{array}{c}\text { FLT3-ITD } \\
\text { mutation group } \\
\mathrm{n}=37(\%)\end{array}$ & $\begin{array}{c}\text { DNMT3A } \\
\text { mutation only } \\
\text { group } \mathrm{n}=32(\%)\end{array}$ & $\begin{array}{c}\text { Control group } \\
n=30(\%)\end{array}$ & $\chi^{2}$ & P-value \\
\hline $\mathrm{CD}_{3} 4^{+}$ & $32(94.12)$ & $34(91.89)$ & $29(90.63)$ & $28(93.33)$ & 0.339 & 0.953 \\
\hline $\mathrm{CD} 117^{+}$ & $31(91.18)$ & 35 (94.59) & $30(93.75)$ & $29(96.67)$ & 0.884 & 0.829 \\
\hline $\mathrm{CD} 15^{+}$ & $29(85.29)$ & $21(56.76)^{\mathrm{a}, \mathrm{b}}$ & $28(87.50)$ & $26(86.67)^{\mathrm{a}, \mathrm{b}}$ & 13.87 & $<0.050$ \\
\hline HLA-DR $^{+}$ & $14(41.18)$ & $3(8.11)^{a, b}$ & $10(31.25)$ & $5(16.67)^{a, b}$ & 12.41 & $<0.050$ \\
\hline $\mathrm{CD}_{13}{ }^{+}$ & $30(88.24)$ & $28(75.68)$ & $28(87.50)$ & $27(90.00)$ & 3.540 & 0.316 \\
\hline $\mathrm{CD}^{+} 3^{+}$ & $32(94.12)$ & $34(91.89)$ & $30(93.75)$ & $29(96.67)$ & 0.673 & 0.880 \\
\hline $\mathrm{CD}_{14}^{+}$ & $3(8.82)$ & $3(8.11)$ & $2(6.25)$ & $2(6.67)$ & 0.207 & 0.976 \\
\hline $\mathrm{CD} 8^{+}$ & $28(82.35)$ & $31(83.78)$ & $9(28.13)^{\mathrm{a}, \mathrm{c}}$ & $13(43.33)^{\mathrm{a}, \mathrm{c}}$ & 33.03 & $<0.001$ \\
\hline
\end{tabular}

${ }^{\mathrm{a}} \mathrm{P}<0.05$ vs. DNMT3A + FLT3-ITD mutation group; ${ }^{\mathrm{b}} \mathrm{P}<0.05$ vs. DNMT3A mutation only group; ${ }^{\mathrm{c}} \mathrm{P}<0.05$ vs. FLT3-ITD mutation group. DNMT3A, DNA methyltransferase 3 $\alpha$; FLT3-ITD, FMS-like tyrosine kinase-internal tandem duplication; CD, cluster of differentiation; HLA-DR, human leukocyte antigen-DR isotype.

Table IV. Chemotherapy efficacy in the four patient groups.

\begin{tabular}{|c|c|c|c|c|c|c|}
\hline Curative effect & $\begin{array}{c}\text { DNMT3A + FLT3-ITD } \\
\text { mutation group } \\
\mathrm{n}=34(\%)\end{array}$ & $\begin{array}{c}\text { FLT3-ITD } \\
\text { mutation only } \\
\text { group } \mathrm{n}=37(\%)\end{array}$ & $\begin{array}{c}\text { DNMT3A } \\
\text { mutation only } \\
\text { group } \mathrm{n}=32(\%)\end{array}$ & $\begin{array}{l}\text { Control group } \\
n=30(\%)\end{array}$ & $\chi^{2}$ & P-value \\
\hline Complete remission & $4(11.76)$ & $14(37.84)$ & $13(40.63)$ & $15(50.00)$ & 13.69 & $<0.001$ \\
\hline Partial remission & $9(26.47)$ & $12(32.43)$ & $10(31.25)$ & $10(33.33)$ & 0.730 & 0.866 \\
\hline Stability of the disease & $14(41.18)$ & $6(16.22)$ & $5(15.63)$ & $3(10.00)$ & 11.58 & $<0.001$ \\
\hline Progress of the disease & $7(20.59)$ & $5(13.51)$ & $4(12.50)$ & $2(6.67)$ & 2.684 & 0.443 \\
\hline Total effective rate & $13(38.24)$ & $26(70.27)^{\mathrm{a}, \mathrm{b}}$ & $23(71.88)^{\mathrm{a}, \mathrm{b}}$ & $25(83.33)^{\mathrm{a}}$ & 16.34 & $<0.050$ \\
\hline
\end{tabular}

${ }^{\mathrm{a}} \mathrm{P}<0.05$ vs. DNMT3A + FLT3-ITD mutation group; ${ }^{\mathrm{P}}<0.05$ vs. control group. DNMT3A, DNA methyltransferase 3 $\alpha$; FLT3-ITD, FMS-like tyrosine kinase-internal tandem duplication.

in the $\mathrm{CR}$ rates when compared with each other $(\mathrm{P}>0.05)$, significantly lower $\mathrm{CR}$ rates were exhibited when they were compared with the control patient group $(\mathrm{P}<0.05)$. The 1-year RR of patients in the DNMT3A + FLT3-ITD mutation patient group was $75.00 \%$, compared with $14.29,15.38$ and $6.67 \%$ in the FLT3-ITD mutation only, DNMT3A mutation only and control patient groups, respectively $(\mathrm{P}<0.05)$. The difference between FLT3-ITD mutation only and DNMT3A mutation only patient groups was not statistically significant $(\mathrm{P}>0.05)$, but these two groups exhibited significantly higher 1-year RR compared with the control patient group $(\mathrm{P}<0.05)$. In the DNMT3A + FLT3-ITD mutation group, patients displayed a 3-year OS rate of $11.76 \%$, which was significantly lower compared with the rates of $43.24,43.75$ and $53.33 \%$ in the FLT3-ITD mutation only, DNMT3A mutation only and control patient groups, respectively $(\mathrm{P}<0.05)$. The difference between the FLT3-ITD mutation only and DNMT3A mutation only groups was not statistically significant $(\mathrm{P}>0.05)$, but these two groups exhibited significantly lower 3-year OS rates compared with the control patient group $(\mathrm{P}<0.05$; Fig. 2; Table V).

\section{Discussion}

AML is a malignant disease of hematopoietic stem cells, and cytogenetic examination is currently the most common method applied for the prognostic evaluation of AML (19). Accumulating evidence has reported that mutations in genes encoding DNMT3A, FLT3-ITD and nucleophosmin 1 occur in AML patients (20). FLT3 encodes a protein that is pivotal for the proliferation and differentiation of human lymphoid progenitor cells (21). The FLT3-ITD mutation is proposed to be associated with the poor prognosis of patients with AML (22). DNMT3A is also a commonly mutated gene in patients with AML, with the third-highest mutation rate of all known genes associated with leukemia (23). DNMT3A mutation is an independent prognostic factor in patients with AML and is useful for risk stratification in determining prognosis. Studies have demonstrated that DNMT3A combined with FLT3-ITD mutation is the most frequent combination of mutations in patients with AML (24,25). A previous study revealed a close association between DNMT3A and FLT3-ITD mutations (26), but studies evaluating the clinical features and prognosis of 
Table V. Comparison of complete remission, 1-year relapse rate, and 3-year overall survival in the four groups of patients.

\begin{tabular}{lcccccc}
\hline Item & $\begin{array}{c}\text { DNMT3A + FLT3-ITD } \\
\text { mutation group } \\
\mathrm{n}=34(\%)\end{array}$ & $\begin{array}{c}\text { FLT3-ITD } \\
\text { mutation only } \\
\text { group n=37 } \%)\end{array}$ & $\begin{array}{c}\text { DNMT3A } \\
\text { mutation only } \\
\text { group n=32 }(\%)\end{array}$ & $\begin{array}{c}\text { Control group } \\
\mathrm{n}=30(\%)\end{array}$ & $\chi^{2}$ & P-value \\
\hline Complete remission & $4(11.76)$ & $14(37.84)^{\mathrm{a}, \mathrm{b}}$ & $13(40.63)^{\mathrm{a}, \mathrm{b}}$ & $15(50.00)^{\mathrm{a}}$ & 11.67 & $<0.050$ \\
1-year relapse rate & $3(75.00)$ & $2(20.00)^{\mathrm{a}, \mathrm{b}}$ & $2(22.22)^{\mathrm{a}, \mathrm{b}}$ & $1(6.67)^{\mathrm{a}}$ & 1057 & $<0.050$ \\
3-year overall survival & $4(11.76)$ & $16(43.24)^{\mathrm{a}, \mathrm{b}}$ & $14(43.75)^{\mathrm{a}, \mathrm{b}}$ & $16(53.33)^{\mathrm{a}}$ & 13.86 & $<0.050$ \\
\hline
\end{tabular}

${ }^{\mathrm{a}} \mathrm{P}<0.05$ vs. DNMT3A + FLT3-ITD mutation group, ${ }^{\mathrm{b}} \mathrm{P}<0.05$ vs. control group. DNMT3A, DNA methyltransferase 3 $\alpha$; FLT3-ITD, FMS-like tyrosine kinase-internal tandem duplication.

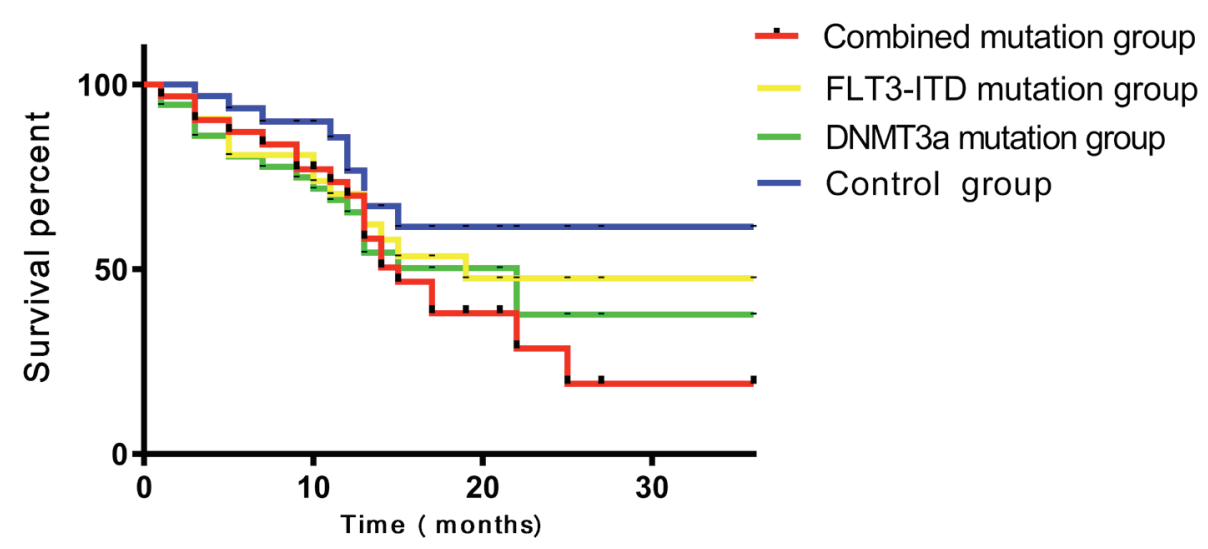

Figure 2. Comparison of 3-year OS in the four patient groups. The 3-year OS of the DNMT3A + FLT3-ITD mutation group was significantly higher compared with that of the FLT3-ITD mutation only, DNMT3A mutation only and control groups. No statistically significant differences between the FLT3-ITD mutation only and DNMT3A mutation only groups were observed, but these two groups displayed significantly lower 3-year OS rates compared with the control group. OS, overall survival; DNMT3A, DNA methyltransferase 3 $\alpha$; FLT3-ITD, FMS-like tyrosine kinase-internal tandem duplication.

patients carrying mutations in DNMT3A and FLT3-ITD in detail are lacking. Therefore, in the present study patients with AML were separated into groups according to mutations in these two genes, and the efficacy of chemotherapy and prognosis for these patients was subsequently explored.

In the present study, the WBC, platelet and hemoglobin counts of as well as the proportion of myeloid progenitor cells among the four patient groups were first compared. There were no significant differences in the platelet counts and hemoglobin levels in the peripheral blood of patients in the four groups $(\mathrm{P}>0.05)$, suggesting that simultaneous mutation of DNMT3A and FLT3-ITD contributes to increased WBC and myeloid progenitor cells. It was previously demonstrated that FLT3-ITD mutation can activate a downstream kinase through the continuous activation of protein tyrosine kinase, thereby triggering signal transduction and further inducing the spontaneous and non-receptor-dependent proliferation of leukocytes (27). However, the role of DNMT3A in cell proliferation remains unclear.

The current study evaluated the immunogenotypes of patients in the four groups. A number of studies have indicated that the immunophenotype may be one of the indicators that can affect the remission rate of patients with AML (28), so it can be hypothesized that CD15 and HLA-DR expression may be associated with the combined mutation of DNMT3A and FLT3-ITD genes, which warrants further investigation. It has been previously reported that, compared with patients harboring no DNMT3A mutations, patients carrying DNMT3A mutation were found to have higher $\mathrm{CD} 34^{+}, \mathrm{CD} 15^{+}$and $\mathrm{HLA}-\mathrm{D}^{+}$rates $(29)$. Furthermore, another previous study revealed that patients carrying FLT3-ITD mutations exhibited higher rates of CD34 ${ }^{+}$ and $\mathrm{CD} 38^{+}$compared with patients without this mutation (30). Therefore, chemotherapy efficacy was compared between the four groups in the current study. The results suggested that patients with simultaneous mutations are associated with poorer chemotherapy efficacy compared with those carrying single mutations. A previous study reported that patients with AML carrying combined FLT3-ITD and DNMT3A mutations have a significantly lower rate of complete response to induction chemotherapy (31), the underlying mechanism of which has not been adequately explained. Finally, CR, 1-year RR and OS rates of patients between the four groups were compared. A previous study investigating the effect of FLT3-ITD and DNMT3A simultaneous mutations on patients with AML suggested that these mutations affect the survival time and can serve as a molecular criterion for prognostic evaluation (32). In addition, Ahn et al (33) evaluated the effect of gene mutations introduced following hematopoietic stem cell transplantation in patients with AML with normal karyotypes. This study revealed that patients harboring simultaneous mutations in DNMT3A and FLT3-ITD demonstrated significantly higher relapse rates and lower event-free survival and OS rates compared with patients 
with wild-type or DNMT3A mutation. Therefore, the results presented in the present study are in agreement with the abovementioned previous observations.

In conclusion, patients with AML carrying simultaneous mutations of FLT3-ITD and DNMT3A demonstrated poor prognosis with lower CR, 1-year RR and OS rates compared with those carrying single mutations in either gene. However, the reason for the clinical remission rate of patients with FLM3-ITD + DNMT3A combined mutations being lower compared with that of patients with FLT3-ITD and DNMT3A single mutations was not explained in the present study. Further studies are required to develop novel therapeutic strategies specific to these gene mutations in patients with AML.

\section{Acknowledgements}

Not applicable.

\section{Funding}

No funding was received.

\section{Availability of data and materials}

The datasets used and/or analyzed during the current study are available from the corresponding author on reasonable request.

\section{Authors' contribution}

QRZ and KH were responsible for study conception and design. Data analysis and interpretation were performed by XW, JC and FG. QRZ was responsible for drafting the article. Critical revision of article was performed by $\mathrm{KH}$. XW, JC and FG performed data collection. All authors read and approved the final manuscript.

\section{Ethics approval and consent to participate}

This study was approved by the Ethics Committee of The Affiliated Zhangjiagang Hospital of Soochow University. All patients and their families agreed to participate in the study and signed written informed consent.

\section{Patient consent for publication}

The patient, or parent, guardian or next of kin (in case of deceased patients) provided written informed consent for the publication of any associated data and accompanying images.

\section{Competing interests}

The authors declare that they have no competing interests.

\section{References}

1. Döhner H, Weisdorf DJ and Bloomfield CD: Acute myeloid leukemia. N Engl J Med 373: 1136-1152, 2015.

2. Mrózek K, Heinonen K and Bloomfield CD: Clinical importance of cytogenetics in acute myeloid leukaemia. Best Pract Res Clin Haematol 14: 19-47, 2001.
3. Papaemmanuil E, Gerstung M, Bullinger L, Gaidzik VI, Paschka P, Roberts ND, Potter NE, Heuser M, Thol F, Bolli N, et al: Genomic classification and prognosis in acute myeloid leukemia. N Engl J Med 374: 2209-2221, 2016.

4. Wolach O and Stone RM: Acute myeloid leukemia. Target Ther Transl Cancer Res 5: 89, 2015.

5. Stone RM, Mandrekar SJ, Sanford BL, Laumann K, Geyer S, Bloomfield CD, Thiede C, Prior TW, Döhner K, Marcucci G, et al: Midostaurin plus chemotherapy for acute myeloid leukemia with a FLT3 mutation. N Engl J Med 377: 454-464, 2017.

6. Kao HW, Liang DC, Kuo MC, Wu JH, Dunn P, Wang PN, Lin TL, Shih YS, Liang ST, Lin TH, et al: High frequency of additional gene mutations in acute myeloid leukemia with MLL partial tandem duplication: DNMT3A mutation only is associated with poor prognosis. Oncotarget 6: 33217-33225, 2015.

7. Ferreira HJ, Heyn H, Vizoso M, Moutinho C, Vidal E, Gomez A, Martínez-Cardús A, Simó-Riudalbas L, Moran S, Jost E and Esteller M: DNMT3A mutations mediate the epigenetic reactivation of the leukemogenic factor MEIS1 in acute myeloid leukemia. Oncogene 35: 3079-3082, 2016.

8. Debarri H, Lebon D, Roumier C, Cheok M, Marceau-Renaut A, Nibourel O, Geffroy S, Helevaut N, Rousselot P, Gruson B, et al: IDH1/2 but not DNMT3A mutations are suitable targets for minimal residual disease monitoring in acute myeloid leukemia patients: A study by the acute leukemia french association. Oncotarget 6: 42345-42353, 2015.

9. Gaidzik VI, Weber D, Paschka P, Kaumanns A, Krieger S, Corbacioglu A, Krönke J, Kapp-Schwoerer S, Krämer D, Horst $\mathrm{H}$, et al: DNMT3A mutant transcript levels persist in remission and do not predict outcome in patients with acute myeloid leukemia. Leukemia 32: 30-37, 2018.

10. Im AP, Sehgal AR, Carroll MP, Smith BD, Tefferi A, Johnson DE and Boyiadzis M: DNMT3A and IDH mutations in acute myeloid leukemia and other myeloid malignancies: Associations with prognosis and potential treatment strategies. Leukemia 28: 1774-1783, 2014.

11. Marhäll A, Heidel F, Fischer T and Rönnstrand L: Internal tandem duplication mutations in the tyrosine kinase domain of FLT3 display a higher oncogenic potential than the activation loop D835Y mutation. Ann Hematol 97: 773-780, 2018.

12. Fleischmann M, Schnetzke U, Schrenk KG, Schmidt V, Sayer HG, Hilgendorf I, Hochhaus A and Scholl S: Outcome of FLT3-ITD-positive acute myeloid leukemia: Impact of allogeneic stem cell transplantation and tyrosine kinase inhibitor treatment. J Cancer Res Clin Oncol 143: 337-345, 2017.

13. Ortlepp C, Steudel C, Heiderich C, Koch S, Jacobi A, Ryser M, Brenner S, Bornhäuser M, Brors B and Hofmann WK: Autotaxin is expressed in FLT3-ITD positive acute myeloid leukemia and hematopoietic stem cells and promotes cell migration and proliferation. Exp Hematol 41: 444-461.e4, 2013.

14. Levis MJ, Perl AE, Altman JK, Gocke CD, Bahceci E, Hill J, Liu C, Xie Z, Carson AR, McClain V, et al: A next-generation sequencing-based assay for minimal residual disease assessment in AML patients with FLT3-ITD mutations. Blood Adv 2: 825-831, 2018.

15. Bashasha SH, Kordofani AA, Osman IM, Musa OH, Altayb HN and Elmagbool BK: Prevalence of the different FAB sub type of acute myeloid leukemia related to hematological parameters in Sudanese. J Hematol Blood Disord 3: 102, 2017.

16. Meyerson H, Sundaram S and Lazarus HM: Bone marrow structure and marrow aspiration, biopsy, and collection for therapeutic intent procedures. In: Lazarus $\mathrm{H}$ and Schmaier A (eds). Concise guide to hematology. Springer, Cham, pp233-252, 2019.

17. Wen H, Yuan L, Wei C, Zhao Y, Qian Y, Ma P, Ding S, Yang X and Wang $X$ : Effects of combined exposure to formaldehyde and benzene on immune cells in the blood and spleen in Balb/c mice. Environ Toxicol Pharmacol 45: 265-273, 2016.

18. Schwartz LH, Litière S, de Vries E, Ford R, Gwyther S, Mandrekar S, Shankar L, Bogaerts J, Chen A, Dancey J, et al: RECIST 1.1-update and clarification: From the RECIST committee. Eur J Cancer 62: 132-137, 2016.

19. Ossenkoppele G: Acute myeloid leukemia. HemaSphere 2: 11, 2018.

20. Tsai CH, Hou HA, Tang JL, Kuo YY, Chiu YC, Lin CC, Liu CY, Tseng MH, Lin TY, Liu MC, et al: Prognostic impacts and dynamic changes of cohesin complex gene mutations in de novo acute myeloid leukemia. Blood Cancer J 7: 663, 2017.

21. Lyman SD, James L, Zappone J, Sleath PR, Beckmann MP and Bird T: Characterization of the protein encoded by the flt 3 (flk2) receptor-like tyrosine kinase gene. Oncogene 8: 815-822, 1993. 
22. Altman JK, Perl AE, Cortes JE, Smith CC, Litzow MR, Hill JE, Larson RA, Liu C, Ritchie EK, Strickland SA, et al: Deep molecular response to gilteritinib to improve survival in FLT3 mutation-positive relapsed/refractory acute myeloid leukemia. J Clin Oncol 35: 7003, 2017.

23. Spencer DH, Russler-Germain DA, Ketkar S, Helton NM, Lamprecht TL, Fulton RS, Fronick CC, O'Laughlin M, Heath SE, Shinawi $\mathrm{M}$, et al: $\mathrm{CpG}$ island hypermethylation mediated by DNMT3A is a consequence of AML progression. Cell 168: 801-816. e13, 2017.

24. Renneville A, Boissel N, Nibourel O, Berthon C, Helevaut N, Gardin C, Cayuela JM, Hayette S, Reman O, Contentin N, et al: Prognostic significance of DNA methyltransferase 3A mutations in cytogenetically normal acute myeloid leukemia: A study by the Acute Leukemia French Association. Leukemia 26: 1247-1254, 2012.

25. Marcucci G, Metzeler KH, Schwind S, Becker H, Maharry K, Mrózek K, Radmacher MD, Kohlschmidt J, Nicolet D, Whitman SP, et al: Age-related prognostic impact of different types of DNMT3A mutations in adults with primary cytogenetically normal acute myeloid leukemia. J Clin Oncol 30: 742-750, 2012.

26. Jost E, Lin Q, Weidner CI, Wilop S, Hoffmann M, Walenda T, Schemionek M, Herrmann O, Zenke M, Brümmendorf T, et al: Epimutations mimic genomic mutations of DNMT3A in acute myeloid leukemia. Leukemia 28: 1227, 2014.

27. Song G, Valdez BC, Li Y, Liu Y, Champlin RE and Andersson BS: Synergistic cytotoxicity of sorafenib with busulfan and nucleoside analogs in human FMS-like tyrosine Kinase 3 internal tandem duplications-positive acute myeloid leukemia cells. Bio Blood Marrow Transplant 20: 1687-1695, 2014.
28. Zhang LJ, Jiang NG, Zhou J, Yuan-Xin YE, Xiao-Jun LU, Ying BW and Jiang H: Immunophenotypic analysis of DNMT3A gene mutations in the patients with acute myeloid leukemia. Chin J Clin Lab Sci, 2014 (In Chinese).

29. Kato N, Kitaura J, Doki N, Komeno Y, Watanabe-Okochi N, Togami K, Nakahara F, Oki T, Enomoto Y, Fukuchi Y, et al: Two types of $\mathrm{C} / \mathrm{EBP} \alpha$ mutations play distinct but collaborative roles in leukemogenesis: Lessons from clinical data and BMT models. Blood 117: 221-233, 2011

30. Schranz K, Hubmann M, Harin E, Vosberg S, Herold T, Metzeler KH, Rothenberg-Thurley M, Janke H, Bräundl K, Ksienzyk B, et al: Clonal heterogeneity of FLT3-ITD detected by high-throughput amplicon sequencing correlates with adverse prognosis in acute myeloid leukemia. Oncotarget 9: 30128-30145, 2018.

31. Yang BY: Research progress of combined mutation of FLT3-ITD and DNMT3A R882 gene in acute myeloid leukemia. Chin Mod Med, 2018 (In Chinese).

32. Gale RE, Lamb K, Allen C, El-Sharkawi D, Stowe C, Jenkinson S, Tinsley S, Dickson G, Burnett AK, Hills RK and Linch DC: Simpson's paradox and the impact of different DNMT3A mutations on outcome in younger adults with acute myeloid leukemia. J Clin Oncol 33: 2072-2083, 2015.

33. Ahn JS, Kim HJ, Kim YK, Lee SS, Jung SH, Yang DH, Lee JJ, Kim NY, Choi SH, Jung CW, et al: DNMT3A R882 mutation with FLT3-ITD positivity is an extremely poor prognostic factor in patients with normal-karyotype acute myeloid leukemia after allogeneic hematopoietic cell transplantation. Biol Blood Marrow Transplant 22: 61-70, 2016. 